\title{
Comportamento térmico de fechamentos em alvenaria estrutural para a Zona Bioclimática 2 brasileira
}

\author{
Thermal behavior of masonry building fence to \\ brazilian climate zone 2
}
Joaquim César Pizzutti dos Santos ${ }^{1}$, Kamila Kappaun Kothe ${ }^{2}$, Gihad Mohamad ${ }^{1}$, Marcos Alberto Oss Vaghetti ${ }^{1}$, Eduardo Rizzatti ${ }^{1}$

\author{
${ }^{1}$ Universidade Federal de Santa Maria - UFSM - Departamento de Estruturas e Construção Civil - DECC, Centro de \\ Tecnologia, Avenida Roraima, Santa Maria, RS. \\ e-mail: joaquimpizzutti@hotmail.com, gihad.civil@gmail.com,marcos.vaghetti@ufsm.br, edu-rizzatti@yahoo.com.br \\ ${ }^{2}$ Arquiteta e Urbanista, Santa Maria, RS. \\ e-mail: kamila2210@gmail.com
}

\begin{abstract}
RESUMO
Este trabalho apresenta os resultados de um estudo de caso que teve por objetivo efetuar uma avaliação comparativa do comportamento térmico de edificações executadas com fechamentos em alvenaria estrutural com o uso de blocos cerâmicos e de concreto. Essa avaliação foi realizada a partir de medições de temperaturas externas e internas, simultaneamente obtidas em duas edificações, entre as quais o diferencial construtivo era apenas o tipo de bloco estrutural utilizado nos fechamentos. Essas edificações localizam-se no mesmo lote, com a mesma posição de implantação na cidade de São Leopoldo-RS, na Zona Bioclimática 2 brasileira. As medições foram efetuadas em dois períodos, uma no inverno e outra no verão, utilizando registradores de temperatura colocados no segundo pavimento e na cobertura, posicionados em ambientes com diferentes orientações solares. Foram analisadas as influências de três variáveis sobre o comportamento térmico: do tipo de bloco, da orientação solar dos fechamentos dos ambientes e dos ganhos térmicos pela cobertura. Como conclusão, observou-se que, tanto no período de inverno como no de verão, ocorreram pequenas diferenças nas temperaturas internas entre os dois edifícios monitorados, indicando pouca influência do tipo de bloco empregado nos fechamentos sobre o comportamento térmico da edificação. As maiores temperaturas e o menor amortecimento térmico ocorrem, no inverno, nos ambientes com parede cega com maior incidência solar, para o norte, e no verão com parede cega para o sul, salientando a importância da incidência da radiação solar sobre os fechamentos opacos. Também, foi observada a influência da cobertura no comportamento térmico, sendo medidas temperaturas mais elevadas e uma maior amplitude térmica nos ambientes do último pavimento das duas edificações, tanto no inverno como no verão.
\end{abstract}

Palavras chaves: Desempenho térmico, blocos estruturais cerâmicos, blocos estruturais de concreto.

\section{ABSTRACT}

This work aims to evaluate a case study of thermal behavior of ceramic and concrete block masonry fences for Brazilian climate zone two. In-place measurements of outside and inside temperature were carried out to obtain the influence of the fences built with ceramic or concrete block. The buildings are localized in the same position at the city of São Leopoldo-RS. The measurements were taken in two periods in winter and summer, using temperature recorders placed on the second floor and rooftop. There were analyzed the influences of three variables on thermal behavior: type of block, solar orientation and the thermal gains of the roof. As a conclusion of this research, it was observed a small difference in the internal temperature for both building in winter and summer, indicating a little influence of the type of the block on the thermical behavior of the fences. The highest temperatures and the lower thermal damping occurred in winter for the walls with higher solar incidence to north and, for summer, for the blind south wall, emphasizing the importance of the solar radiation incidence for 
the opaque fences. It was obtained in winter and summer a high temperature and a wider thermal range for the roof.

Keywords: Thermal Performance, structural ceramic block, structural concrete block.

\section{INTRODUÇÃO}

Cada vez mais, os sistemas construtivos devem ser repensados de forma a incluir as considerações energéticas e ambientais no projeto, harmonizando as construções, a fim de aperfeiçoar as relações entre o homem e a natureza, tanto no que diz respeito à redução de impactos ambientais quanto à melhoria da qualidade de vida. Neste contexto, conhecer o comportamento térmico dos fechamentos das edificações permite aos projetistas estabelecerem estratégias para que as construções possam responder de maneira eficiente às variações climáticas, fornecendo as condições técnicas necessárias para o atendimento de critérios mínimos de desempenho, oferecendo conforto ao usuário, minimizando o uso de equipamentos e o consumo de energia. Nesse sentido, as normas regulam o desempenho térmico e a eficiência energética das edificações, especificam os critérios e os requisitos para que os projetos e a execução das construções considerem as características climáticas locais e garantam um desempenho térmico mínimo, sendo importante o reconhecimento dessas normas por parte do meio técnico brasileiro.

A entrada em vigor da norma NBR 15575-1 [1] estabelece uma referência com base nos requisitos para o desempenho mínimo ao longo da vida útil para os elementos principais de qualquer edificação habitacional, entre estes os fechamentos verticais opacos, ponto de interesse desse trabalho. Essa norma é um divisor de águas, estabelecendo um marco regulatório, técnico e jurídico no setor de edificações. Conceitos de vida útil são estabelecidos e as várias incumbências são atribuídas aos incorporadores, construtores, projetistas, fornecedores e usuários, por meio de critérios mínimos de desempenho da edificação. Com relação à alvenaria estrutural, uma tecnologia construtiva empregada no Brasil, é importante o resultado de pesquisas que relatem o comportamento e o desempenho térmico desse sistema, verificando comparativamente as diferentes opções de blocos estruturais, pois no país é produzida uma ampla variedade de blocos, tanto de vedação como estruturais, existindo dúvidas no setor de construção civil sobre qual é o tipo e o material mais adequado para atender às necessidades do desempenho térmico, considerando os diferentes climas do território brasileiro. Visto que, a avaliação comparativa da influência do uso de diferentes materiais sobre o desempenho térmico de edificações é de difícil análise, já que muitos parâmetros construtivos têm influência conjunta sobre esse comportamento, como planta baixa, orientação solar, localização da construção, entre outros. Dessa forma, a maioria das pesquisas utiliza a simulação computacional, a qual permite a seleção das variáveis convenientes à análise, além de utilizar arquivos climáticos adequados ao local de implantação da edificação.

Este trabalho teve como objetivo principal avaliar comparativamente o comportamento térmico de dois materiais utilizados nos fechamentos em alvenaria estrutural, o bloco de concreto e o bloco cerâmico, no intuito de obter dados de medições sobre o comportamento térmico de edificações executadas com esses dois tipos de blocos. Para isso, foi realizado um estudo de caso, no qual foram estudados dois prédios que possuem a mesma planta baixa, cada qual construído com um dos tipos de blocos citados, edificados em um mesmo condomínio habitacional, localizados lado a lado, com a mesma posição de implantação, na cidade de São Leopoldo/RS, situada na Zona Bioclimática 2 brasileira. As duas edificações foram analisadas nos mesmos períodos, sem ocupação e vedadas, para que os resultados pudessem ser comparados sem a interferência de variáveis que não fossem interessantes aos objetivos do trabalho. O comportamento térmico foi avaliado a partir da análise comparativa entre as temperaturas internas e externas medidas nas duas edificações, sendo verificadas separadamente as influências do tipo de bloco, da orientação solar dos fechamentos dos ambientes monitorados, além do fato do andar medido ser de cobertura. O desempenho térmico dos fechamentos foi avaliado de acordo com as recomendações de valores limites dos parâmetros térmicos citados pela NBR 15220 [4] e pelo atendimento aos critérios mínimos estabelecidos pelo método simplificado da norma NBR 15575-4 [2].

\section{REVISÃO BIBLIOGRÁFICA}

\subsection{Zoneamento bioclimático brasileiro}

O Brasil possui vários climas e é justamente por essa variedade de climas que a Associação Brasileira de Normas Técnicas apresenta o zoneamento bioclimático brasileiro na NBR 15220-3 [5], "Desempenho térmico de edificações - Parte 3: zoneamento bioclimático brasileiro e diretrizes construtivas para habitações unifamiliares de interesse social". Este zoneamento adotado divide o território brasileiro em oito (8) Zonas Bioclimáticas. A divisão levou em conta o clima de cada local atribuindo a classificação zonal para as regiões com homogenei- 
dade quanto às médias mensais das temperaturas máximas, mínimas e as médias mensais da umidade relativa do ar. Essa classificação bioclimática fornece recomendações construtivas para um melhor desempenho térmico das edificações, adequando estratégias de projeto para o clima local, de forma a proporcionar melhor conforto térmico. Para cada Zona Bioclimática existem diferentes diretrizes construtivas que são recomendadas, abrangendo as dimensões e proteções das aberturas, as vedações externas (tipos de cobertura, tipos de parede e piso) e estratégias de condicionamento térmico passivo. O Rio Grande do Sul possui em sua extensão três (3) diferentes Zonas Bioclimáticas. A cidade de São Leopoldo-RS, onde foi realizado o estudo de caso, encontra-se na Zona Bioclimática 2, indicada na Figura 1.

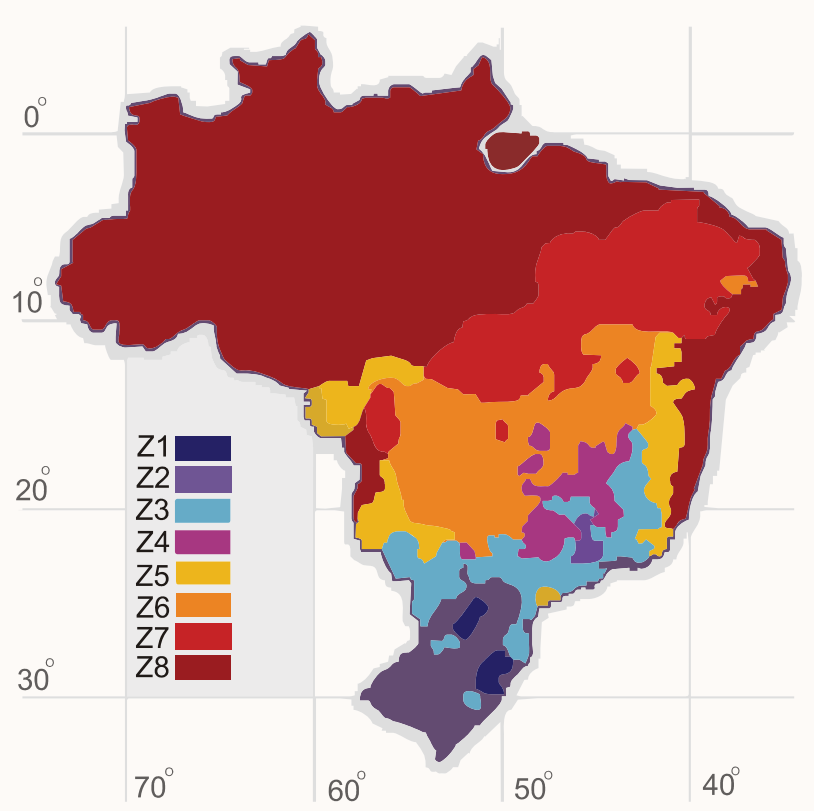

Figura 1: Zoneamento bioclimático do Brasil (NBR 15220-3 [5]).

\subsection{Cálculo da transmitância térmica, atraso térmico e fator solar}

A seguir são demonstradas as equações para a determinação dos parâmetros de isolamento térmico de um sistema de fechamento de acordo com a NBR 15220-1 [3]. A resistência térmica é obtida a partir da Equação 01, dependendo da espessura da camada de material (e) e da condutividade térmica $(\lambda)$ do mesmo.

$$
R=\frac{e}{\lambda}
$$

Este cálculo é feito para cada uma das seções das camadas do material, sendo que a resistência para cada seção $\left(\mathrm{R}_{\mathrm{t}}\right)$ não ventilada é obtida de acordo com a Equação 02, considerando a existência de seções com diferentes resistências térmicas.

$$
R_{t}=\frac{A_{a}+A_{b}+\ldots+A_{n}}{\frac{A_{a}}{R_{a}}+\frac{A_{b}}{R_{b}}+\cdots+\frac{A_{n}}{R_{n}}}
$$

Onde, $A_{a}, A_{b}, \ldots . ., A_{n}$ são as áreas de cada seção; $R_{a}, R_{b}, \ldots . ., R_{n}$ são as resistências térmicas de superfície à superfície para cada seção.

A resistência térmica de superfície a superfície é dada pela Equação 03.

$$
R_{T}=R_{S e}+R_{t}+R_{S i}
$$

Onde, $R_{T}$ é a resistência térmica de superfície a superfície; $R_{S e}$ e $R_{S i}$ são as resistências superficiais externas e internas, cujos valores são obtidos na NBR 15220-1 [3]. Com isso, se obtém a transmitância térmica 
(U) de acordo com a Equação 04 .

$$
U=\frac{1}{R_{T}}
$$

Outro parâmetro importante para análise do desempenho é a capacidade térmica de componentes $\left(\mathrm{C}_{\mathrm{T}}\right)$, obtida de acordo com a equação 05 .

$$
C_{T}=\sum_{i=1}^{n} \lambda_{i} \cdot R_{i} \cdot c_{i} \cdot \rho_{i}=\sum_{i=1}^{n} e_{i} \cdot c_{i} \cdot \rho_{i}
$$

Onde, $\lambda_{\mathrm{i}}=$ é a condutividade térmica do material da primeira camada; $\mathrm{R}_{\mathrm{i}}=$ é a resistência térmica da primeira camada; $\mathrm{e}_{\mathrm{i}}=$ é a espessura da primeira camada; $\mathrm{c}_{\mathrm{i}}=$ é o calor específico do material da primeira camada; $\rho_{\mathrm{i}}=$ é a densidade de massa aparente do material da primeira camada.

Como o ar apresenta uma densidade de massa aparente muito baixa $\left(\rho=1,2 \mathrm{~kg} / \mathrm{m}^{3}\right)$, a sua capacidade térmica, em componentes com câmaras de ar, pode ser desprezada. Portanto, a capacidade térmica de um componente é dada pela equação 06 .

$$
C_{T}=\frac{A_{a}+A_{b+\cdots+} A_{n}}{\frac{A_{a}}{C_{T a}}+\frac{A_{b}}{C_{T b}}+\cdots+\frac{A_{n}}{C_{T n}}}
$$

Onde, $A_{a}, A_{b}, \ldots . ., A_{n}$ são as áreas de cada seção; $C_{\mathrm{Ta}}, C_{T b}, \ldots \ldots . ., C_{T n}$ são as capacidades térmicas do componente para cada seção determinada de acordo com a Equação 05.

Considerando a parede como uma composição de materiais distintos pode ser determinado o atraso térmico $(\varphi)$ de acordo com a Equação 07.

$$
\varphi=1,382 \cdot R_{T} \cdot \sqrt{B_{1}+B_{2}}
$$

Onde, $\mathrm{R}_{\mathrm{T}}$ é a resistência térmica de superfície a superfície do componente; $\mathrm{B}_{1}$ é dado pela Equação 08 ; $\mathrm{B}_{2}$ é dado pela Equação 09; $\mathrm{B}_{\mathrm{o}}$ é dado pela Equação $10 ; \mathrm{C}_{\mathrm{T}}$ é a capacidade térmica total do componente; $\mathrm{C}_{\text {Text }} \mathrm{e}$ a capacidade térmica da camada externa do componente. $\mathrm{O}$ fator solar de ganho de calor para elementos opacos é dado pela Equação (11).

$$
\begin{gathered}
B_{1}=0,226 \cdot \frac{B_{o}}{R_{T}} \\
B_{2}=0,205 .\left(\frac{(\lambda \cdot \rho \cdot c)_{\text {ext }}}{R_{T}}\right) \cdot\left(R_{\text {ext }}-\frac{R_{T-} R_{\text {ext }}}{10}\right) \\
B_{o}=C_{T}-C_{\text {Text }} \\
F S_{o}=100 \cdot U \cdot \alpha \cdot R_{S e}
\end{gathered}
$$

Onde, $\mathrm{FS}_{\mathrm{o}}$ é o fator solar dos elementos opacos em percentagem; U é a transmitância térmica do componente; $\alpha$ é a absortância à radiação solar da superfície - função da cor; $\mathrm{R}_{\mathrm{Se}}$ é a resistência superficial externa. Como $\mathrm{R}_{\mathrm{Se}}$ é admitido constante e igual a 0,04, a Equação 11 pode ser reescrita na forma da Equação 12.

$$
F S_{o}=4 \cdot U \cdot \alpha
$$

A norma NBR 15220-2 [4] apresenta as diretrizes construtivas específicas para cada Zona Bioclimática 
brasileira. No caso deste trabalho foram analisadas as recomendações para a Zona Bioclimática 2, da qual a cidade de São Leopoldo faz parte. A Tabela 1 apresenta as recomendações para a Zona Bioclimática 2 brasileira.

Tabela 1: Recomendações para a Zona Bioclimática 2, conforme NBR 15220-2 [4].

\begin{tabular}{|c|c|c|}
\hline \multicolumn{3}{|c|}{ Zona Bioclimática 2} \\
\hline \multirow[t]{2}{*}{ Aberturas } & Aberturas para ventilação médias & $\begin{array}{c}15 \%<\text { A }<25 \% \\
A(\text { em \% da área do piso) }\end{array}$ \\
\hline & Sombreamento & Permitir o sol durante o inverno \\
\hline \multirow{3}{*}{ Paredes externas leves } & Transmitância térmica - U (W/m².K) & $\leq 3,0$ \\
\hline & Atraso térmico $\varphi(\mathrm{h})$ & $\leq 4,3$ \\
\hline & Fator solar $-F S_{o}(\%)$ & $\leq 5,0$ \\
\hline \multirow{3}{*}{ Cobertura leve e isolada } & Transmitância térmica - U (W/m².K) & $\leq 2,0$ \\
\hline & Atraso térmico $-\varphi(\mathrm{h})$ & $\leq 3,3$ \\
\hline & Fator solar $-F S_{o}(\%)$ & $\leq 6,5$ \\
\hline \multirow{3}{*}{$\begin{array}{l}\text { Estratégias de condiciona- } \\
\text { mento térmico passivo }\end{array}$} & Verão & Ventilação cruzada \\
\hline & \multirow{2}{*}{$\begin{array}{c}\text { Inverno } \\
* \mathrm{O} \text { condicionamento passivo é insuficiente neste } \\
\text { período }\end{array}$} & Aquecimento solar \\
\hline & & Vedações internas pesadas \\
\hline
\end{tabular}

\subsection{Norma brasileira NBR 15575 (2013)}

A norma NBR 15575 denominada de "Edificações habitacionais - Desempenho" é um conjunto de normas organizadas em seis partes. A mesma se preocupa com a edificação como um todo, estabelecendo critérios e métodos de avaliação de desempenho para os principais sistemas que compõem um edifício, abordando temas relacionados a sistemas estruturais, sistemas de pisos internos, sistemas de vedações verticais internas e externas, sistemas de coberturas e sistemas hidrossanitários. Esse conjunto de normas é abrangente e define requisitos de desempenho que se aplicam ao edifício habitacional através de critérios de segurança, habitabilidade, higiene, saúde, durabilidade e adequação ambiental, considerando as necessidades dos usuários e as condições de exposição da edificação ao longo de sua vida útil mínima obrigatória. A NBR 15575-4 [2] estabelece a possibilidade de avaliação do desempenho térmico por três métodos: um método simplificado, em que os parâmetros térmicos dos fechamentos são comparados com valores limites estabelecidos pela norma, o método de medições e o método por simulação computacional, nos quais o critério de avaliação é a comparação entre os valores medidos ou simulados de temperatura interna e externa máximos no verão e mínimos no inverno. O método simplificado de análise estabelece os critérios mínimos de desempenho térmico de vedações verticais e cobertura, estabelecendo valores admissíveis para transmitância térmica $(\mathrm{U})$ e capacidade térmica $\left(\mathrm{C}_{\mathrm{T}}\right)$, de acordo com a Zona Bioclimática em que a edificação está inserida. Além disso, a norma traz recomendações sobre as aberturas, estabelecendo áreas mínimas de ventilação e sombreamento das janelas. A Tabela 2 apresenta os critérios estabelecidos para uso desse método da NBR 15575-4 [2], para a Zona Bioclimática 2.

Tabela 2: Recomendações para o desempenho térmico mínimo de vedações verticais e cobertura na Zona Bioclimática 2 , segundo a NBR 15575-4 [2].

\begin{tabular}{|c|c|c|}
\hline \multicolumn{2}{|c|}{ Vedações Verticais e Cobertura para Zona Bioclimática 2 - Nível de Desempenho Mínimo } \\
\hline Requisito & \multicolumn{2}{|c|}{ Critérios } \\
\hline $\begin{array}{c}\text { Vedações } \\
\text { Externas }\end{array}$ & Transmitância térmica $-\mathrm{U}\left(\mathrm{W} /\left(\mathrm{m}^{2} . \mathrm{K}\right)\right)$ & $\leq 2,5$ \\
\cline { 2 - 3 } & Capacidade térmica $\left(\mathrm{KJ} /\left(\mathrm{m}^{2} . \mathrm{K}\right)\right)$ & $\geq 130$ \\
\hline $\begin{array}{c}\text { Ventilação dos ambientes } \\
\text { internos à habitação }\end{array}$ & $\begin{array}{c}\text { Áreas mínimas de aberturas para ventila- } \\
\text { ção }(\mathrm{A}, \mathrm{em} \% \text { da área do piso) }\end{array}$ & $\mathrm{A} \geq 7 \%$ \\
\hline $\begin{array}{c}\text { Sombreamento das abertu- } \\
\text { ras } \\
\text { localizadas em paredes } \\
\text { externas }\end{array}$ & $\begin{array}{c}\text { Sombreamento dos vãos das janelas de } \\
\text { dormitórios }\end{array}$ & $\begin{array}{c}\text { Uso de dispositivos de sombreamento que } \\
\text { permitam o controle de sombreamento e } \\
\text { escurecimento a critério do usuário }\end{array}$ \\
\hline Cobertura & Transmitância térmica $-\mathrm{U}\left(\mathrm{W} /\left(\mathrm{m}^{2} . \mathrm{K}\right)\right)$ & $\leq 2,5$ \\
\cline { 2 - 3 } & Absortância térmica & Sem exigência \\
\hline
\end{tabular}

Como critérios e níveis de avaliação de desempenho térmico através de medições ou simulação, para a Zona Bioclimática 2 brasileira, a NBR 15575-1 [1] estabelece as condições apresentadas na Tabela 3. Para o emprego do método por medições, a norma enumera condições específicas para realização das mesmas, as quais 
não foram seguidas na totalidade nesse estudo. Mesmo assim, nesse trabalho foi realizada uma análise por esse método, considerando os períodos de medições e a metodologia empregada no mesmo.

Tabela 3: Critérios para avaliação de desempenho térmico pelo método de medição na Zona Bioclimática 2, segundo NBR 15575-1 [1]

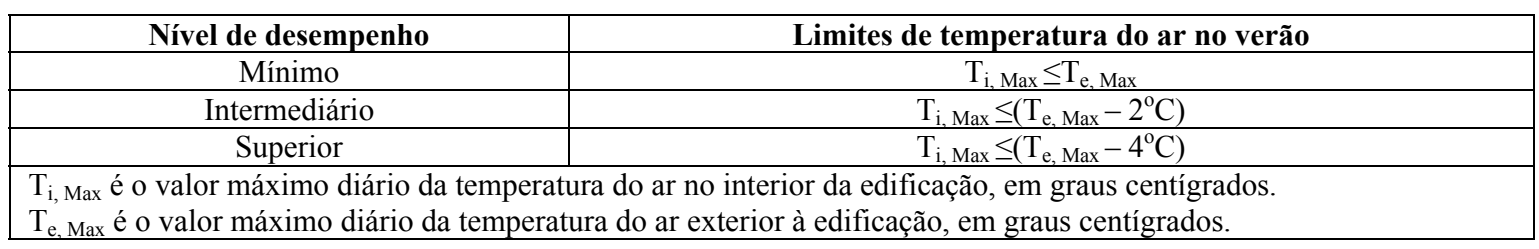

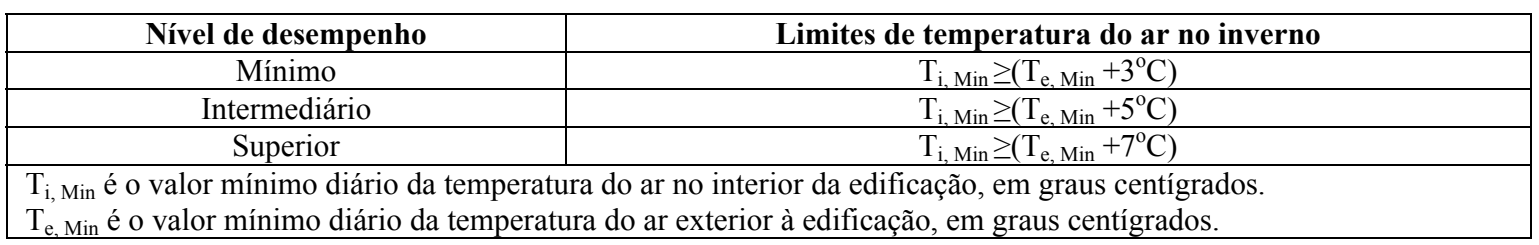

\subsection{Tipos de blocos para alvenaria estrutural}

No sistema em alvenaria estrutural existe uma ampla variedade de blocos que servem para o emprego na transmissão de esforços e visam atender às necessidades técnicas da edificação. Os blocos de concreto são unidades estruturais vazadas, vibrocompactadas e produzidas por indústrias de pré-fabricação de concreto, encontrados no Brasil apenas com paredes maciças (NBR 15961 [7]). Os blocos estruturais cerâmicos classificam-se em: bloco cerâmico de paredes vazadas; bloco cerâmico com paredes maciças; bloco cerâmico com paredes maciças (paredes internas vazadas) e bloco cerâmico perfurado (NBR 15812 [6]). Na região Sul do Brasil, os mais empregados são os blocos de concreto e cerâmico de parede vazada, como mostra a Figura 2.
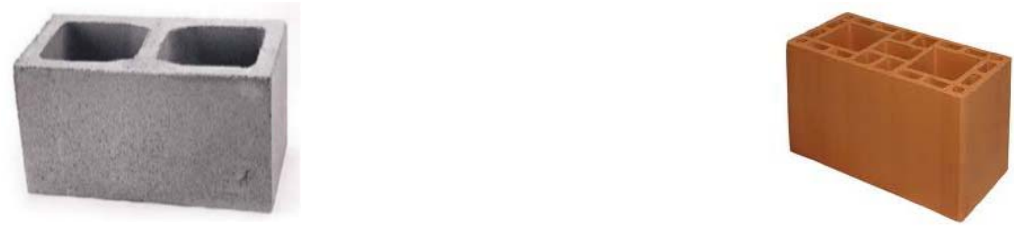

Figura 2: Exemplos de blocos de concreto e cerâmico.

Al-Hadhrami [9] avaliou o desempenho térmico dos diferentes tipos de unidades de bloco usados na Arábia Saudita, que devido ao deserto é caracterizado como um clima quente de dia e frio à noite. A Tabela 4 apresenta as geometrias dos blocos, com a adição ou preenchimento dos vazados com poliestireno ou perlita. 
Tabela 4: Geometrias dos blocos com as designações de tipo.

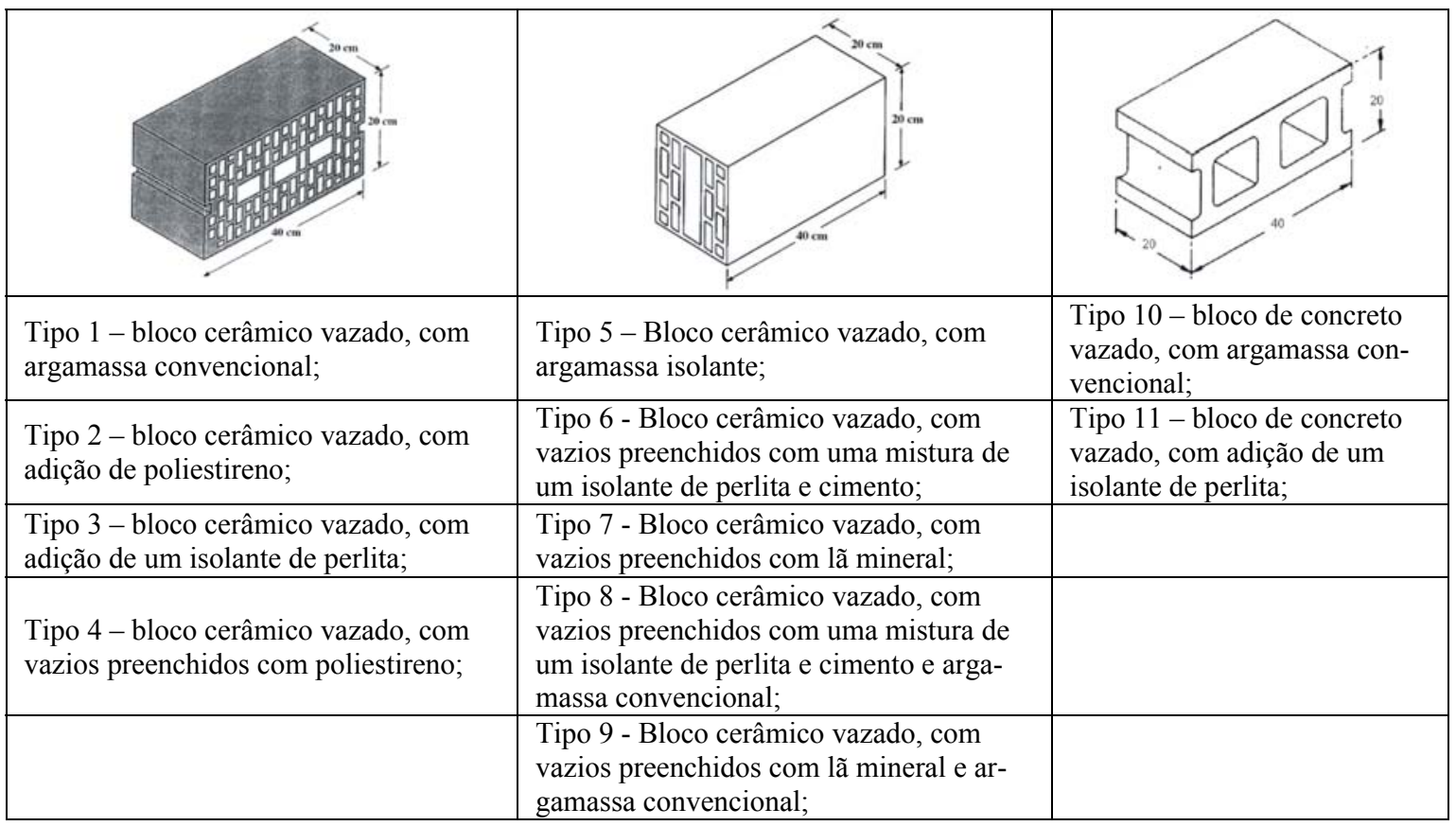

A Figura 3 apresenta a resistência térmica dos blocos cerâmicos, de acordo com os tipos de materiais empregados nos estudos de Al-Hadhrami [9]. Verifica-se que os blocos tipo 1 a 9 e com isolamento obtiveram uma resistência térmica maior em relação aos blocos tipo 10 e 11 . O bloco de concreto com argamassa convencional foi o que apresentou a menor resistência térmica em relação aos demais. Para este tipo de bloco, a simples adição do isolante perlita aumentou, aproximadamente, em $100 \%$ a resistência térmica da unidade. Observa-se que os blocos cerâmicos apresentaram as maiores resistências térmicas em relação aos blocos de concreto. $\mathrm{O}$ autor cita que o uso de argamassa convencional afetou o desempenho térmico do conjunto, pois, pela continuidade da junta, age como uma ponte térmica.

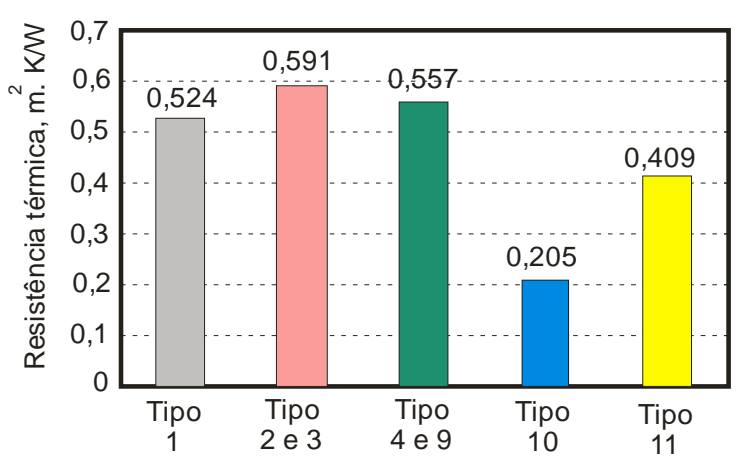

Figura 3: Resistência térmica dos diferentes tipos de unidades (Al-Hadhrami [9]]).

Chichierchio [10], a partir de ensaios realizados no IPT, traz várias propriedades de alvenarias com blocos cerâmicos e de concreto, que até o momento são referências no meio técnico nacional. Algumas propriedades foram resumidas por Thomaz e Helene [13], sendo reproduzidas na Figura 4. 


\begin{tabular}{|c|c|c|c|c|}
\hline \multirow[b]{2}{*}{ Tipo de bloco } & \multirow[b]{2}{*}{ Largura do bloco $(\mathrm{cm})$} & \multicolumn{3}{|c|}{ Características da parede } \\
\hline & & $\begin{array}{c}\text { Largura } \\
(\mathrm{cm})\end{array}$ & $\begin{array}{c}\text { Massa } \\
\left(\mathrm{Kg} / \mathrm{m}^{2}\right)\end{array}$ & $\begin{array}{l}\text { Resist. Térmica } \\
\left(\mathrm{m}^{2} .{ }^{\circ} \mathrm{C} / \mathrm{W}\right)\end{array}$ \\
\hline \multirow{3}{*}{ Pe } & \multirow{2}{*}{9} & 9 & 90 & * \\
\hline & & 12 & 130 & 0,22 \\
\hline & 14 & 17 & 180 & 0,30 \\
\hline \multirow{3}{*}{4} & \multirow{2}{*}{9} & 9 & 130 & $*$ \\
\hline & & 12 & 170 & 0,11 \\
\hline & 14 & 17 & 215 & $*$ \\
\hline & \multirow{2}{*}{14} & 14 & 120 & 0,31 \\
\hline & & 17 & 160 & $*$ \\
\hline & \multirow[b]{2}{*}{14} & 14 & 175 & 0,16 \\
\hline & & 17 & 215 & $*$ \\
\hline
\end{tabular}

*Ensaios não realizados;

Figura 4: Características de resistência térmica de paredes de blocos vazados (Thomaz e Helene [13]).

Grabarz et al. [12], utilizando os dados acima, para paredes de blocos de concretos e cerâmicos de $14 \mathrm{~cm}$, com e sem revestimento, fez um estudo simplificado sobre a adequação dessas paredes aos requisitos da NBR 15220-3 [5]. Os autores concluíram que a espessura do revestimento considerado tem grande influência nos resultados. Alguns exemplos citados no estudo foram o caso da alvenaria cerâmica para as zonas 01 e 02, adequada somente quando combinada a $1,0 \mathrm{~cm}$ de emboço interno e 2,0 $\mathrm{cm}$ de emboço externo (pintura externa amarela ou branca). No caso da Zona Bioclimática 02, na verificação simplificada, os autores concluem que apenas as alvenarias de blocos cerâmicos com revestimento atenderam aos requisitos quando feita a análise das paredes. Outro caso foi da alvenaria de blocos de concreto para as Zonas Bioclimáticas 03, 05 e 08, com diversas espessuras de emboço interno e externo, porém, somente quando pintada externamente de branco foi considerada adequada. Já o autor Zechmeister [14] relatou um estudo sobre desempenho térmico de alvenarias de blocos cerâmicos (maciços, de paredes vazadas ou de paredes maciças) e de blocos vazados de concreto e concluiu que, a partir de uma análise simplificada, considerando apenas a parede, o uso de bloco com $14 \mathrm{~cm}$ de espessura e revestimento externo de $2 \mathrm{~cm}$ e interno de $1 \mathrm{~cm}$ é suficiente para garantir o desempenho térmico do componente construtivo em mais de $70 \%$ das cidades brasileiras.

\section{ESTUDO DE CASO}

O Rio Grande do Sul possui em sua extensão três (3) diferentes Zonas Bioclimáticas. A cidade onde foi realizado este estudo - São Leopoldo/RS - encontra-se na Zona Bioclimática 2. Para cada Zona Bioclimática existem diferentes diretrizes construtivas que são recomendadas, abragendo as dimensões, proteções das aberturas, as vedações externas e as estratégias de condicionamento térmico passivo. Neste trabalho, em que as análises foram efetuadas em função das variações de temperatura interna e externa em edificações em alvenaria estrutural de blocos de concreto e cerâmico, foram monitoradas duas edificações construídas lado a lado no mesmo condomínio habitacional e com mesma distribuição em planta. A Figura 5 apresenta os dois tipos de edifícios executados (Creta e Malta), enquanto a Figura 6 mostra a planta baixa dos edifícios, na qual está assinalado o posicionamento dos registradores de temperatura utilizados, tipo HOBO modelo H08-003-02, e a área de cada ambiente. 

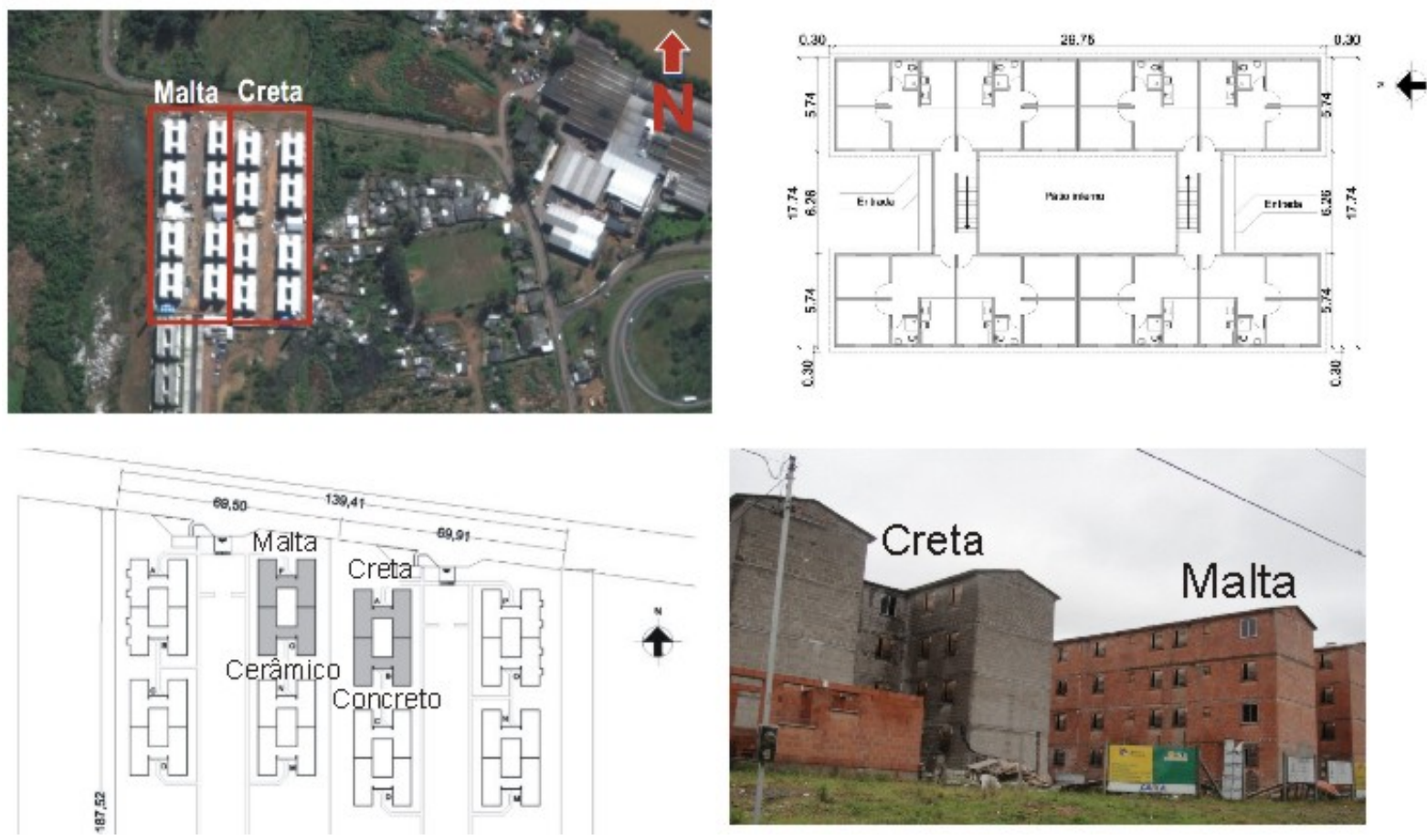

Figura 5: Disposição das edificações em alvenaria de blocos de concreto e cerâmico.

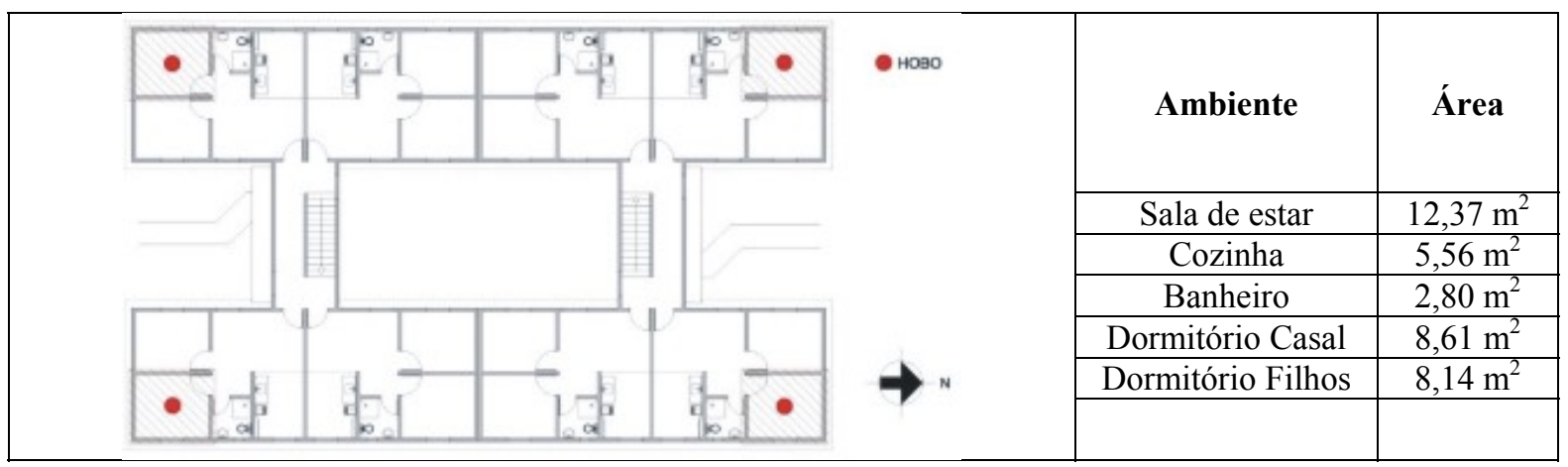

Figura 6: Posição das medições e áreas de cada apartamento.

As paredes internas e externas das edificações foram executadas com blocos estruturais de concreto e de cerâmica com espessura de $14 \mathrm{~cm}$, mostrados na Figura 7, possuindo acabamento interno e externo de argamassa de revestimento de dois (2) $\mathrm{cm}$, o que faz com que a espessura total da parede seja de $18 \mathrm{~cm}$. A pintura externa foi na cor bege claro em ambos os edifícios.
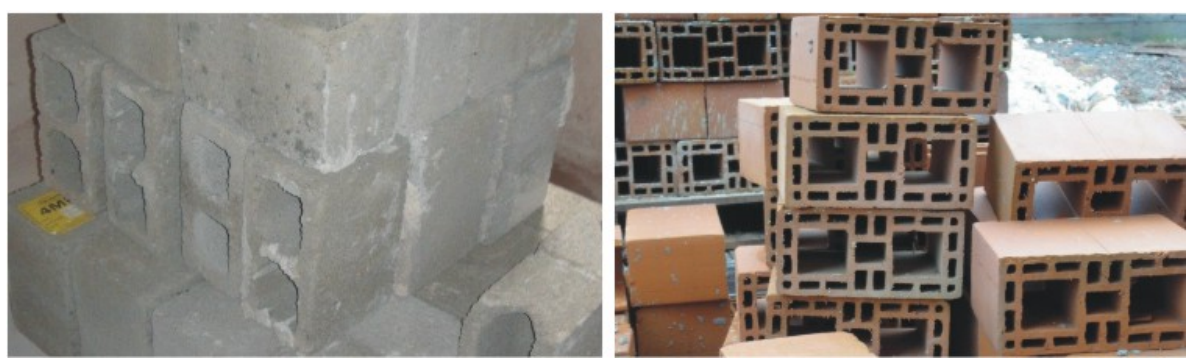
Figura 7: Formato dos blocos de concreto e cerâmico empregados nas edificações.

A cobertura da edificação é em telha de fibrocimento, com laje de entrepiso e de cobertura em concreto armado, pré-moldadas no canteiro com espessura de $10 \mathrm{~cm}$, com beiral de $30 \mathrm{~cm}$ em todo o perímetro externo. $\mathrm{Na}$ cobertura existem aberturas de ventilação isoladas na cumeeira e elementos vazados com furos na horizontal nas faces laterais (oitões) da alvenaria, que permitem a troca de ar no espaço entre a laje de cobertura e a telha de fibrocimento, como destacado na Figura 8.

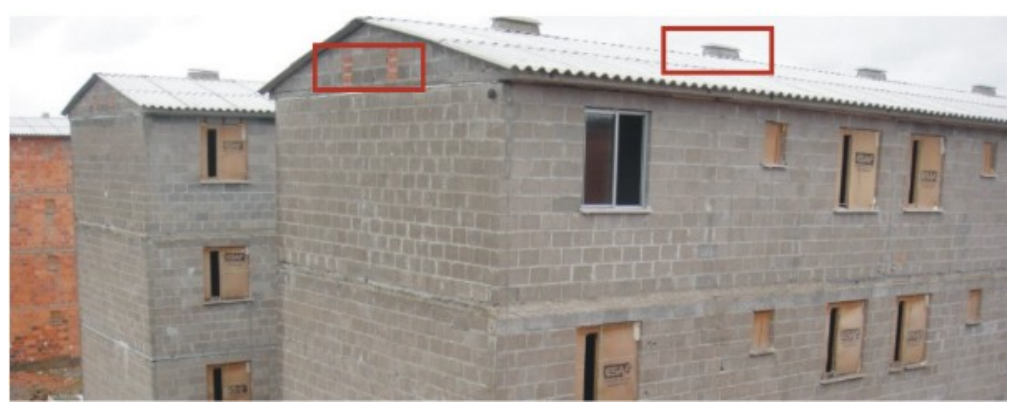

Figura 8: Posições dos dutos horizontais e verticais de ventilação da cobertura.

As janelas do edifício são em alumínio, com duas folhas de correr, sendo as dimensões nos dormitórios, salas e cozinhas de $1,00 \times 1,20 \mathrm{~m}$, com vidro liso incolor de três (3) mm, com área efetiva de ventilação de $50 \%$ do vão. Os blocos estruturais de concreto, cerâmico e as argamassas empregadas nas edificações apresentam as características listadas na Tabela 5.

Tabela 5: Características dos blocos e argamassas empregados no estudo.

\begin{tabular}{|c|c|c|c|}
\hline & Bloco concreto & Bloco cerâmico & Argamassa \\
\hline Dimensões $(\mathrm{cm})$ & $14 \times 19 \times 29$ & $14 \times 19 \times 29$ & - \\
\hline Resistência à compressão & $4,0 \mathrm{MPa}$ & $7,0 \mathrm{MPa}$ & - \\
\hline Peso $(\mathrm{g})$ & 9915 & 6039 & - \\
\hline Área bruta $\left(\mathrm{cm}^{2}\right)$ & 409,88 & 406 & - \\
\hline Densidade $\left(\mathrm{kg} / \mathrm{m}^{3}\right)$ & 2400 & 1957 & - \\
\hline Condutividade térmica $-\lambda(\mathrm{W} / \mathrm{m} . \mathrm{K})$ & 1,75 & 1,05 & 1,15 \\
\hline Calor específico $-\mathrm{c}(\mathrm{kJ} /(\mathrm{kg} . \mathrm{K}))$ & 1,00 & 0,92 & 1,00 \\
\hline
\end{tabular}

A partir dos valores da Tabela 5 foram realizados, por meio dos procedimentos definidos pela NBR 15220-2 [4], os cálculos dos parâmetros de desempenho térmico dos dois tipos de fechamentos externos das edificações estudadas nesse trabalho, obtendo-se a transmitância térmica $(\mathrm{U})$, a capacidade térmica $\left(\mathrm{C}_{\mathrm{t}}\right)$, o atraso térmico $(\varphi)$ e o fator solar (FS), de acordo com as diferentes seções de cada bloco apresentadas na Tabela 6. Ambas as edificações foram consideradas sem o uso de graute para o cálculo de todos os parâmetros. Observase na Tabela 6 que o fechamento com o bloco cerâmico resulta em valores menores de transmitância térmica e capacidade térmica. Isto ocorre pelo maior número de espaços de ar no interior deste tipo de bloco e o menor valor de condutividade térmica e de peso específico do material. Na Tabela 7 são apresentados os valores limites fixados pelas normas brasileiras de desempenho, evidenciando o cumprimento ou não dos limites pelas alvenarias analisadas.

Tabela 6: Valores de resistência térmica, transmitância térmica, capacidade térmica, atraso térmico e fator solar para o bloco estrutural de concreto e cerâmico.

\begin{tabular}{|c|c|c|}
\hline & Bloco de concreto & Bloco cerâmico \\
\hline Resistência térmica da parede $\left(\mathrm{m}^{2} \cdot \mathrm{K}\right) / \mathrm{W}$ & 0,18 & 0,31 \\
\hline Resistência térmica total $\left(\mathrm{m}^{2} \cdot \mathrm{K}\right) / \mathrm{W}$ & 0,35 & 0,48 \\
\hline Transmitância térmica $-\mathrm{U}\left(\mathrm{W} /\left(\mathrm{m}^{2} \cdot \mathrm{K}\right)\right)$ & 2,88 & 2,09 \\
\hline Capacidade térmica $-\mathrm{C}_{\mathrm{t}}\left(\mathrm{KJ} /\left(\mathrm{m}^{2} \cdot \mathrm{K}\right)\right)$ & 264,31 & 194,17 \\
\hline Atraso térmico $-\varphi(\mathrm{h})$ & 4,19 & 4,54 \\
\hline Fator Solar $-F S_{o}(\%)=0,25$ & 2,88 & 2,09 \\
\hline
\end{tabular}




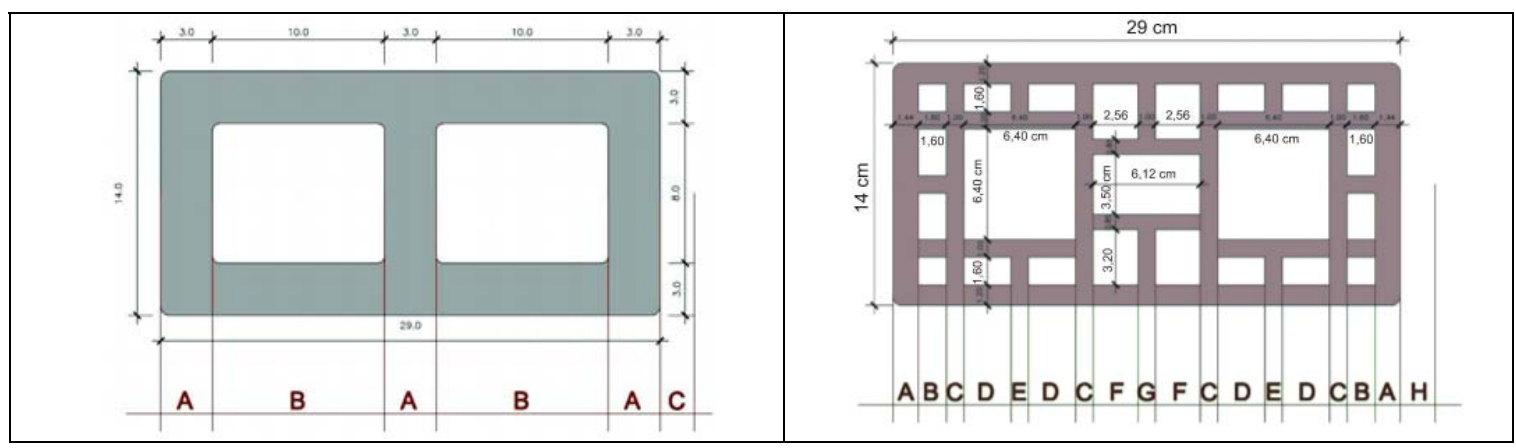

Tabela 7: Comparação das propriedades térmicas calculadas dos blocos estudados com os limites das normas brasileiras de desempenho.

\begin{tabular}{|c|c|c|c|c|c|c|c|}
\hline $\begin{array}{c}\text { Norma } \\
\text { Brasileira }\end{array}$ & Zona Bioclimática & $\underset{\left(\mathbf{W} / \mathbf{m}^{2}\right)}{\mathbf{U}_{\lim }}$ & $\begin{array}{c}\mathrm{U} \\
\text { Concr. }\end{array}$ & $\begin{array}{c}\text { U } \\
\text { Cerâm. }\end{array}$ & $\begin{array}{l}\varphi_{\lim } \\
\text { (hs) }\end{array}$ & $\begin{array}{c}\varphi \\
\text { Concr. }\end{array}$ & $\begin{array}{c}\varphi \\
\text { Cerâm. }\end{array}$ \\
\hline \multirow{3}{*}{$\begin{array}{c}\text { NBR } \\
15220-2 \\
{[4]}\end{array}$} & 1 e 2 & $\leq 3,00$ & 2,88 & 2,09 & $\leq 4,3$ & 4,2 & 4,5 \\
\hline & 3,5 e 8 & $\leq \mathbf{3 , 6 0}$ & 2,88 & 2,09 & $\leq 4,3$ & 4,2 & 4,5 \\
\hline & 4,6 e 7 & $\leq \mathbf{2 , 2 0}$ & 2,88 & 2,09 & $\geq 6,5$ & 4,2 & 4,5 \\
\hline \multirow{7}{*}{$\begin{array}{c}\text { NBR } \\
15575-4 \\
{[2]}\end{array}$} & $1 \mathrm{e} 2$ & $\leq \mathbf{2 , 5 0}$ & 2,88 & 2,09 & - & - & - \\
\hline & 3 a 8 & \multirow{2}{*}{$\leq \mathbf{3 , 7 0}$} & \multirow{2}{*}{2,88} & \multirow{2}{*}{2,09} & \multirow{2}{*}{ - } & \multirow{2}{*}{-} & \multirow{2}{*}{-} \\
\hline & $\alpha \leq 0,6$ & & & & & & \\
\hline & 3 a 8 & \multirow{2}{*}{$\leq \mathbf{2 , 5 0}$} & \multirow{2}{*}{2,88} & \multirow{2}{*}{2,09} & \multirow{2}{*}{-} & \multirow{2}{*}{ - } & \multirow{2}{*}{ - } \\
\hline & $\alpha \geq 0,6$ & & & & & & \\
\hline & 1 a 7 & - & - & - & - & - & - \\
\hline & 8 & - & - & - & - & - & - \\
\hline $\begin{array}{c}\text { Norma } \\
\text { Brasileira }\end{array}$ & Zona Bioclimática & $\mathrm{FS}_{\mathrm{lim}}(\%)$ & $\begin{array}{c}\mathrm{FS}_{\mathrm{o}} \\
\text { Concr. }\end{array}$ & $\begin{array}{c}\mathrm{FS}_{\mathrm{o}} \\
\text { Cerâm }\end{array}$ & $\begin{array}{c}\mathrm{C}_{\mathrm{tlim}} \\
\mathrm{KJ} /\left(\mathrm{m}^{2} . \mathrm{K}\right)\end{array}$ & $\begin{array}{c}\mathrm{C}_{\mathrm{t}} \\
\text { Concr. }\end{array}$ & $\begin{array}{c}\mathrm{C}_{\mathrm{t}} \\
\text { Cerâm }\end{array}$ \\
\hline \multirow{3}{*}{$\begin{array}{c}\text { NBR } \\
15220-2 \\
{[4]}\end{array}$} & $1 \mathrm{e} 2$ & $\leq \mathbf{5 , 0}$ & 2,9 & 2,1 & - & - & - \\
\hline & 3,5 e 8 & $\leq 4,0$ & 2,9 & 2,1 & - & - & - \\
\hline & 4,6 e 7 & $\leq 3,5$ & 2,9 & 2,1 & - & - & - \\
\hline \multirow{7}{*}{$\begin{array}{c}\text { NBR } \\
15575-4 \\
{[2]}\end{array}$} & 1 e 2 & - & - & - & - & - & - \\
\hline & 3 a 8 & \multirow[b]{2}{*}{-} & \multirow{2}{*}{-} & \multirow[b]{2}{*}{-} & \multirow{2}{*}{ - } & \multirow{2}{*}{-} & \multirow[b]{2}{*}{ - } \\
\hline & $\alpha \leq 0,6$ & & & & & & \\
\hline & 3 a 8 & \multirow[b]{2}{*}{ - } & \multirow{2}{*}{-} & \multirow{2}{*}{ - } & \multirow{2}{*}{ - } & \multirow{2}{*}{-} & \multirow{2}{*}{ - } \\
\hline & $\alpha \geq 0,6$ & & & & & & \\
\hline & 1 a 7 & - & - & - & $\geq 130$ & 264,1 & 194,2 \\
\hline & 8 & - & - & - & Sem lim & 264,1 & 194,2 \\
\hline
\end{tabular}

Os limites de transmitância térmica (U) são diferentes nas duas normas existentes, sendo que, considerando a NBR 15220-2 [4], os fechamentos verticais executados com ambos os blocos têm valores abaixo do máximo estabelecido para todas as Zonas Bioclimáticas. Já para a NBR 15575-4 [2], o fechamento com bloco de concreto apresenta valor superior ao limite máximo estabelecido para as zonas 1 e 2 e, ainda, para as demais zonas se o coeficiente de absorção das paredes for superior a 0,6 , não cumprindo a norma, enquanto que o bloco cerâmico cumpre a norma para todas as zonas.

O atraso térmico $(\varphi)$ somente é considerado na NBR 15220-2 [4]. O valor do fator solar $\left(\mathrm{FS}_{\mathrm{o}}\right)$ também é considerado apenas para NBR 15220-2 [4], sendo que o valor dos fechamentos com ambos os blocos é inferior ao máximo estabelecido, visto que ambas as edificações possuem pintura de cores claras. A capacidade térmica $\left(\mathrm{C}_{\mathrm{t}}\right)$ é considerada como limite pela NBR 15575-4 [2], para as zonas 1 a 7, sendo que ambos os blocos apresentam valores superiores ao valor mínimo estabelecido, caracterizando como fechamentos de inércia térmica elevada.

No estudo de caso do desempenho térmico das edificações em bloco de concreto e cerâmico foram selecionados 16 apartamentos para serem efetuadas as medições de temperaturas, sendo oito (8) apartamentos em cada edifício e, destes, quatro (4) apartamentos no segundo pavimento e quatro (4) apartamentos no quarto pavimento. O segundo pavimento foi escolhido por não sofrer interferência do calor proveniente da cobertura, favorecendo a análise da orientação solar. Já o quarto pavimento foi selecionado justamente por esta interferência, o que permitiu a análise da diferença de comportamento devido à cobertura. Com o objetivo de analisar as orientações solares em cada um dos edifícios foram monitorados quatro (4) apartamentos, sendo: apartamento 
(1), janela voltada a leste e parede cega a norte; apartamento (2), janela voltada a leste e parede cega a sul; apartamento (3), janela voltada a oeste e parede cega a norte; e apartamento (4), janela voltada a oeste e parede cega a sul, como mostra a Figura 9. As medições foram realizadas nas mesmas posições nos apartamentos, independentemente do tipo de bloco, da orientação solar e do andar em que se encontravam.

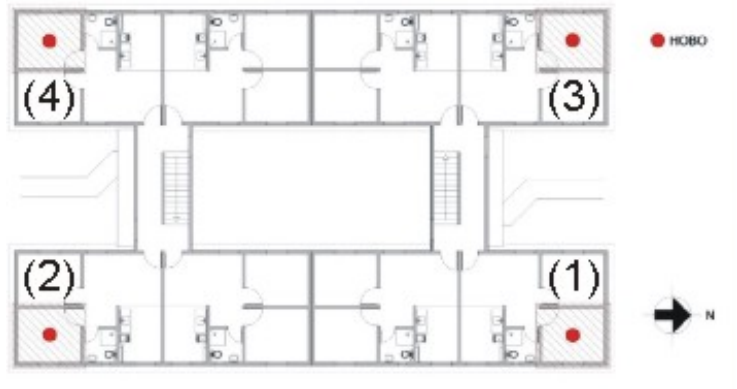

Figura 9: Planta baixa básica do apartamento.

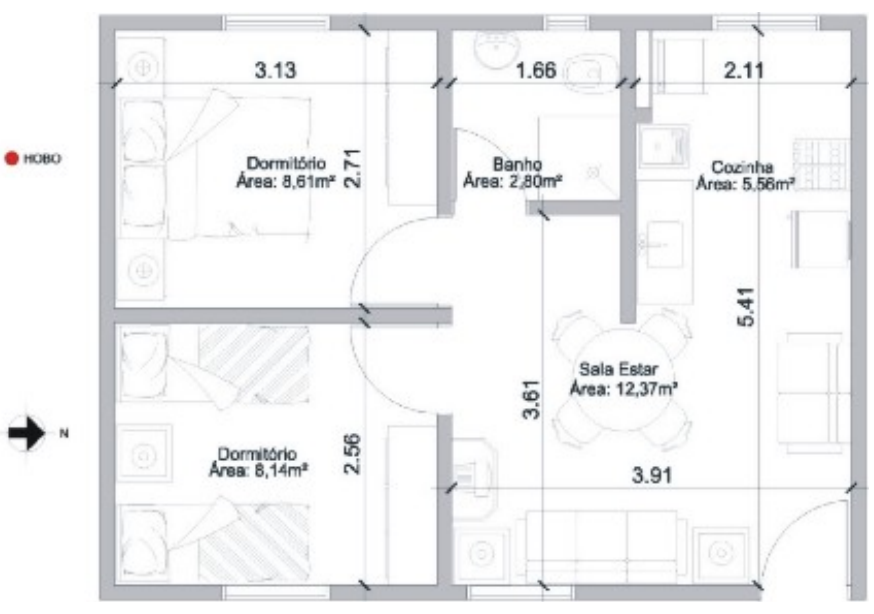

As medições foram realizadas por um período de 15 dias em apartamentos desocupados e fechados, para avaliar o desempenho térmico sem a interferência da variação de outras variáveis, como a ventilação e ganhos internos de calor. As temperaturas internas foram monitoradas simultaneamente nas duas edificações em um período de inverno e outro de verão, juntamente com medidas de temperaturas externas. Como as edificações possuem a mesma orientação solar, mesma planta baixa, mesma localização e regime de ventos semelhantes, estas condicionantes puderam ser desconsideradas como variáveis do estudo.

\section{RESULTADOS}

As diferenças de comportamento térmico foram evidenciadas a partir das variações térmicas internas, analisadas comparativamente entre os andares da mesma edificação, tendo como base as orientações solares e os dois tipos de blocos (concreto e cerâmico), sempre relacionando com as variações das temperaturas externas. Foram realizadas três análises de comportamento térmico, envolvendo as influências sobre a variação da temperatura interna, do tipo de bloco estrutural utilizado, da orientação solar e da cobertura. Para todas as análises foram considerados apenas os dados de temperaturas dos três dias mais significativos dos períodos de medição, sendo esses os de menores temperaturas mínimas no inverno e de maiores temperaturas máximas no verão.

\subsection{Influência do tipo de bloco}

A análise principal do trabalho, referente ao comportamento térmico das edificações com diferentes tipos de blocos, foi realizada fazendo um comparativo entre a média das temperaturas medidas em todas as quatro (4) orientações consideradas no segundo pavimento de cada edificação, com o intuito de considerar conjuntamente as diferentes orientações solares e eliminar a influência da cobertura, itens analisados separadamente nesse trabalho. A Figura 10 apresenta para o bloco de concreto e a Figura 11 para o bloco cerâmico os resultados de temperaturas internas em comparação às temperaturas externas no andar intermediário dos dois edifícios, considerando as diferentes orientações solares e estações do ano. A Tabela 8 lista os valores das médias de temperaturas máximas e mínimas do segundo pavimento consideradas das medições nos três dias de inverno e de verão, sendo calculados a amplitude térmica, o amortecimento da onda térmica e o atraso térmico, o que permite uma análise comparativa do comportamento térmico dos edifícios com diferentes tipos de blocos, para os dois períodos de medição. A legenda das Figuras 10 e 11 mostram orientação das janelas (J) e paredes (P). 


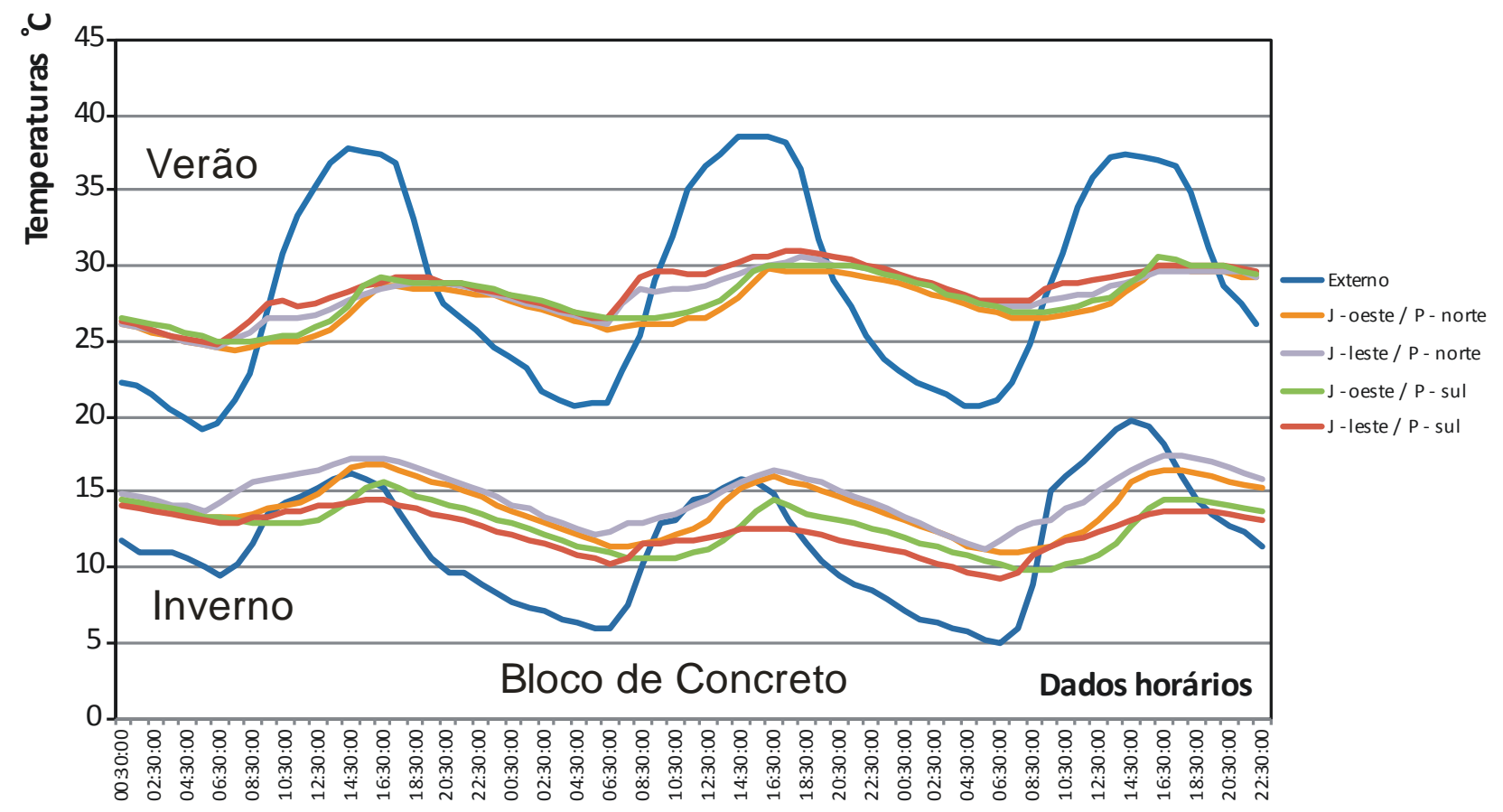

Figura 10: Variação das temperaturas externa e interna no verão e no inverno - bloco de concreto.

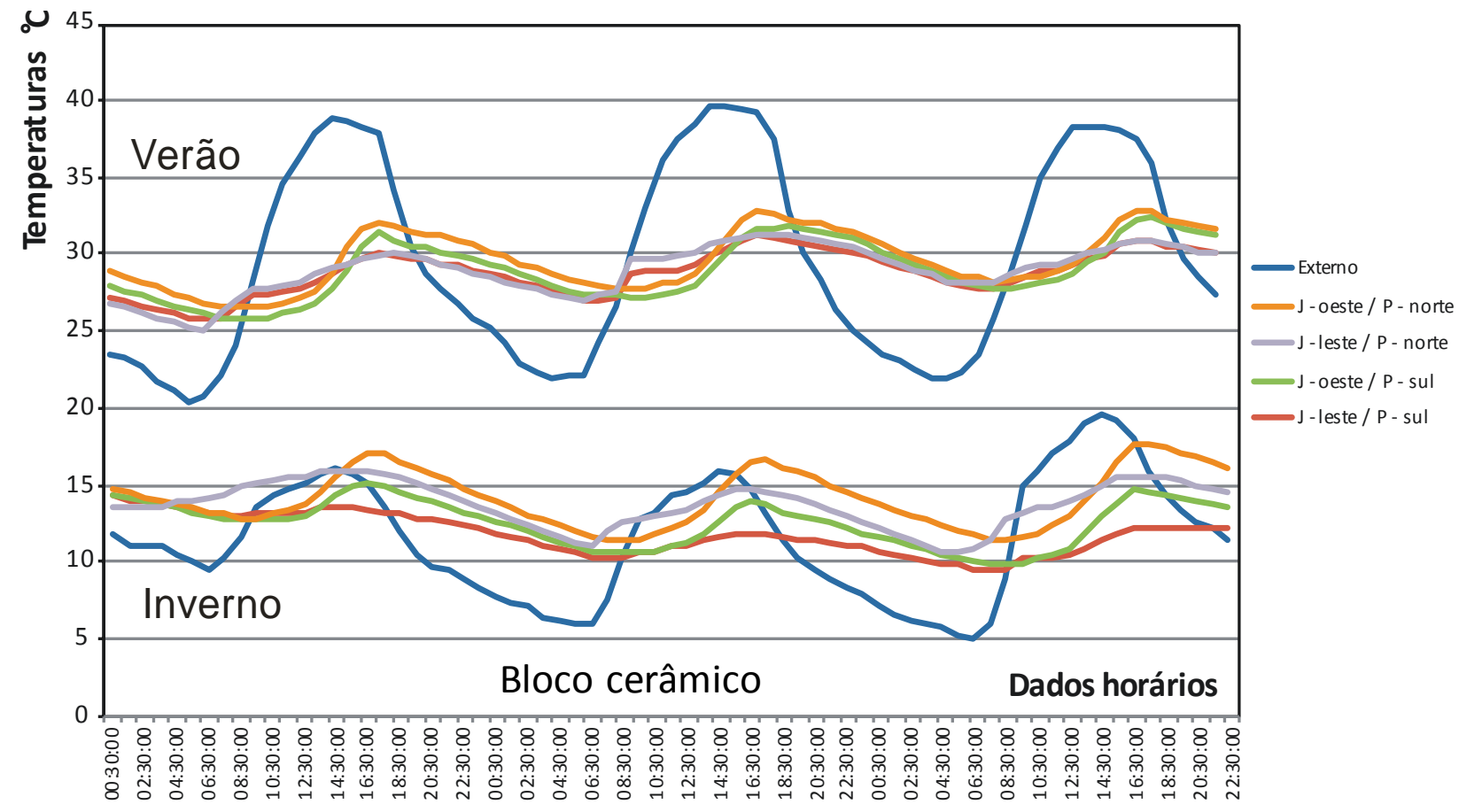

Figura 11: Variação das temperaturas externa e interna no verão e no inverno - bloco cerâmico.

Tabela 8: Temperaturas máximas e mínimas, atraso térmico e amortecimento para diferentes tipos de bloco e períodos de medição.

\begin{tabular}{|c|c|c|c|c|c|c|}
\hline Período & Tipo de Bloco & Média Mín( $\left.{ }^{\circ} c\right)$ & $\begin{array}{c}\text { Média } \\
\text { Máx. }\left({ }^{\circ} \mathrm{c}\right)\end{array}$ & $\begin{array}{c}\text { Amplit. } \\
\left.\text { Média( }{ }^{\circ} \mathrm{c}\right)\end{array}$ & Amort.(\%) & $\begin{array}{c}\text { Atraso } \\
\text { Térmico(hs) } \\
\end{array}$ \\
\hline \multirow{3}{*}{ Inverno } & Concreto & 11,5 & 15,5 & 4,0 & 63,3 & $1: 30$ \\
\hline & Cerâmico & 11,3 & 15,1 & 3,8 & 64,9 & $1: 45$ \\
\hline & Temp. Externa & 6,4 & 17,3 & 10,9 & - & - \\
\hline \multirow{3}{*}{ Verão } & Concreto & 26,2 & 30,1 & 3,9 & 78,1 & $2: 35$ \\
\hline & Cerâmico & 26,0 & 30,8 & 4,8 & 73,0 & $3: 05$ \\
\hline & Temp. Externa & 20,3 & 38,1 & 17,8 & - & - \\
\hline
\end{tabular}


Para o período de inverno, em que os ganhos térmicos pela parede cega têm maior influência sobre o comportamento térmico das edificações, não foram encontradas diferenças significativas nas temperaturas internas devido ao tipo de bloco, não evidenciando a maior transmitância térmica do bloco de concreto.

Para o período de verão, o comportamento térmico nas duas edificações foi semelhante, porém as temperaturas máximas e a amplitude térmica foram um pouco maiores na edificação de bloco estrutural cerâmico, com alguns picos mais acentuados de temperatura, tanto nas máximas quanto nas mínimas, provavelmente devido à menor inércia térmica (capacidade térmica) desse tipo de bloco.

A alta capacidade térmica dos fechamentos analisados tem reflexo direto no expressivo amortecimento da onda térmica. No inverno, esse fato favorece no período noturno, elevando as temperaturas mínimas, mas desfavorece durante o dia, pois reduz as temperaturas máximas. No verão, o comportamento térmico é favorecido nos horários mais quentes, pois as temperaturas máximas são reduzidas, mas nos horários mais frescos da noite, as temperaturas no interior são superiores devido ao calor acumulado nas paredes com alta capacidade térmica durante o dia. Esse fato pode ser compensado caso haja a possibilidade de ventilação noturna.

As diferenças de temperaturas entre os edifícios construídos com os dois tipos de blocos são reduzidas. Isso indica que o tipo de bloco tem pouca influência no comportamento térmico das edificações estudadas, tanto no período de inverno como no verão.

\subsection{Influência da Orientação Solar}

Para a segunda análise realizada, referente à influência da orientação solar no desempenho térmico, foram considerados apenas os valores de temperatura do segundo pavimento das edificações, de forma a eliminar a influência da cobertura. Foram verificadas separadamente as edificações com os diferentes tipos de blocos, considerando os dormitórios das unidades habitacionais com janelas orientadas a leste e a oeste, conforme mostrado na planta de localização dos registradores de temperatura, tendo estes ambientes o diferencial de terem paredes cegas na orientação norte ou sul, resultando quatro orientações solares.

As variações de temperaturas para as diferentes orientações solares estão apresentadas nas Figuras 10 e 11, enquanto na Tabela 9 estão sintetizados os valores mais expressivos de temperaturas máximas e mínimas, amplitude térmica, amortecimento e atraso da onda térmica, os quais permitem uma análise mais detalhada da influência da orientação solar no desempenho térmico de edifícios com diferentes tipos de blocos estruturais nos períodos de inverno e verão.

Tabela 9: Temperaturas máximas e mínimas, atraso térmico e amortecimento para diferentes orientações - bloco de concreto e cerâmico.

\begin{tabular}{|c|c|c|c|c|c|c|c|}
\hline $\begin{array}{c}\text { Período } \\
\text { Medição }\end{array}$ & $\begin{array}{l}\text { Tipo de } \\
\text { Bloco }\end{array}$ & Orientação & $\begin{array}{c}\text { Média } \\
\text { Mín. } \\
\left({ }^{\circ} \mathbf{c}\right) \\
\end{array}$ & $\begin{array}{c}\text { Média } \\
\text { Máx. } \\
\left({ }^{0} \mathrm{c}\right) \\
\end{array}$ & $\begin{array}{c}\text { Amplit. } \\
\text { Média } \\
(\Delta t)\end{array}$ & $\begin{array}{c}\text { Amort. } \\
\text { Médio } \\
(\%) \\
\end{array}$ & $\begin{array}{c}\text { Atraso } \\
\text { Médio } \\
\text { (hs) }\end{array}$ \\
\hline \multirow{9}{*}{ Inverno } & \multirow{4}{*}{ Concreto } & Janela O-Parede N & 11,9 & 16,4 & 4,5 & 58,0 & $1: 40$ \\
\hline & & Janela L-Parede N & 12,3 & 17,0 & 4,7 & 57,0 & $1: 20$ \\
\hline & & Janela O-Parede S & 11,1 & 15,1 & 4,0 & 62,5 & $2: 00$ \\
\hline & & Janela L-Parede S & 10,7 & 13,7 & 3,0 & 72,4 & $1: 00$ \\
\hline & \multirow{4}{*}{ Cerâmico } & Janela O-Parede N & 11,9 & 17,2 & 5,3 & 50,0 & $2: 40$ \\
\hline & & Janela L-Parede N & 11,8 & 15,5 & 3,7 & 66,5 & $1: 20$ \\
\hline & & Janela O-Parede S & 11,1 & 15,0 & 3,9 & 64,5 & $2: 00$ \\
\hline & & Janela L-Parede S & 10,6 & 12,8 & 2,2 & 78,8 & $1: 00$ \\
\hline & & Temp. Externa & 6,4 & 17,3 & 10,9 & - & - \\
\hline \multirow{9}{*}{ Verão } & \multirow{4}{*}{ Concreto } & Janela O-Parede N & 25,8 & 29,7 & 3,9 & 77,8 & $2: 20$ \\
\hline & & Janela L-Parede N & 26,2 & 29,9 & 3,7 & 79,4 & $3: 40$ \\
\hline & & Janela O-Parede S & 26,3 & 30,5 & 4,2 & 76,7 & $2: 00$ \\
\hline & & Janela L-Parede S & 26,5 & 30,3 & 3,8 & 78,7 & $3: 20$ \\
\hline & \multirow{5}{*}{ Cerâmico } & Janela O-Parede N & 26,5 & 31,7 & 5,2 & 70,9 & $3: 00$ \\
\hline & & Janela L-Parede N & 25,7 & 29,8 & 4,1 & 77,4 & $3: 20$ \\
\hline & & Janela O-Parede S & 25,9 & 31,9 & 6,0 & 66,2 & $3: 00$ \\
\hline & & Janela L-Parede S & 25,8 & 29,8 & 3,9 & 77,9 & $3: 00$ \\
\hline & & Temp.Externa & 20,3 & 38,1 & 17,8 & - & - \\
\hline
\end{tabular}

Durante todo o período analisado de inverno, em que a trajetória solar tem ângulos de alturas menores, observa-se que, com ambos os blocos, as menores médias de mínimas e de máximas e o maior amortecimento térmico ocorrem nos ambientes que tem janelas para leste e parede cega para sul, orientações com menores in- 
cidências solares, resultando menores variações de temperaturas internas. Já as maiores médias de temperaturas máximas, mínimas e menores amortecimentos ocorrem em ambientes que têm a parede cega com orientação Norte, a qual tem uma alta incidência de radiação.

Nesse caso, em ambos os prédios, as temperaturas máximas ocorrem no período da tarde, o que indica maior influência dos ganhos pela parede Norte do que pela janela. A média das temperaturas máximas tem a maior diferença de $3,3^{\circ} \mathrm{C}$ entre as diferentes orientações para o bloco de concreto e de $4,4^{\circ} \mathrm{C}$ para o bloco cerâmico, o que indica uma influência importante da orientação solar nos picos de máximas no inverno. Nas médias das mínimas, a diferença é menor: de $1,6^{\circ} \mathrm{C}$ e $1,3^{\circ} \mathrm{C}$ respectivamente, pois ocorrem sempre à noite e refletem $\mathrm{o}$ efeito conjunto da temperatura diurna e da inércia térmica dos componentes do edifício.

Durante o verão fica menos evidente a influência da orientação solar, com diferenças menores nas temperaturas internas entre as curvas das Figuras $10 \mathrm{e} 11$. Nesse caso, o amortecimento térmico ocorre pela redução das temperaturas máximas, e aumento das mínimas, devido à capacidade térmica dos fechamentos que absorve calor durante o dia, reduzindo a temperatura interna, e restitui à noite elevando a temperatura.

No período de verão, com altura solar mais elevada em relação ao Norte, as temperaturas máximas foram medidas no dormitório com janela Oeste e parede cega Sul, para ambos os blocos. As temperaturas mínimas ocorreram em ambientes com parede cega no lado Norte, com janela a Oeste na edificação de bloco de concreto, e com a janela para o Leste quando o bloco é cerâmico. Devido à menor intensidade da radiação solar sobre a face Norte no verão, as temperaturas internas nas diferentes orientações solares têm diferenças menores, com $0,8^{\circ} \mathrm{C}$ e $2,1^{\circ} \mathrm{C}$ entre a maior e a menor média de máximas para o bloco de concreto e de cerâmica, respectivamente. Para as médias de mínimas, esses valores são ainda menores, de $0,7^{\circ} \mathrm{C}$ e $0,8^{\circ} \mathrm{C}$.

No inverno o amortecimento térmico tem diferença máxima entre as orientações de $15,4 \%$ (concreto) e de 18,8\% (cerâmica), enquanto para o verão essas diferenças são de 2,7\% e 11,7\%, respectivamente, o que também indica maior influência da orientação solar no período de inverno.

\subsection{Influência da Cobertura}

Nessa análise avaliou-se a importância da cobertura nas trocas térmicas dessa tipologia de edifício, sendo feito um estudo comparativo entre as temperaturas internas obtidas no segundo pavimento (2 PAV) e as obtidas no pavimento de cobertura (4 PAV). Para esse estudo foi considerado o valor médio das quatro medições realizadas em cada andar, cujos resultados são apresentados na Figura 12, enquanto na Tabela 10 são apresentados os principais valores comparativos encontrados para o inverno e verão, respectivamente.

Tabela 10: Temperaturas máximas e mínimas, atraso térmico e amortecimento para pavimento intermediário e de cobertura.

\begin{tabular}{|c|c|c|c|c|c|c|c|}
\hline $\begin{array}{c}\text { Período } \\
\text { Medição }\end{array}$ & $\begin{array}{l}\text { Tipo de } \\
\text { Bloco }\end{array}$ & Pavimento & $\begin{array}{l}\text { Média } \\
\text { Mín. } \\
\left({ }^{\circ} \mathrm{C}\right)\end{array}$ & $\begin{array}{l}\text { Média } \\
\text { Máx. } \\
\left({ }^{\circ} \mathrm{C}\right)\end{array}$ & $\begin{array}{c}\text { Amplit. } \\
\text { Média } \\
\Delta \mathrm{t})\end{array}$ & $\begin{array}{c}\text { Amort. } \\
\text { Médio(\%) }\end{array}$ & $\begin{array}{c}\text { Atraso } \\
\text { Médio } \\
\varphi(\mathrm{hs})\end{array}$ \\
\hline \multirow{5}{*}{ Inverno } & \multirow{2}{*}{ Concreto } & $2^{\circ}$ andar & 11,5 & 15,6 & 4,1 & 62,5 & $2: 00$ \\
\hline & & Cobertura & 11,8 & 16,4 & 4,6 & 57,9 & $2: 20$ \\
\hline & \multirow{2}{*}{ Cerâmico } & $2^{\circ}$ Andar & 11,4 & 15,1 & 3,7 & 66,1 & $2: 40$ \\
\hline & & Cobertura & 11,6 & 15,6 & 4,0 & 63,8 & $2: 40$ \\
\hline & & Temp. Externa & 6,4 & 17,3 & 10,9 & - & - \\
\hline \multirow{5}{*}{ Verão } & \multirow{2}{*}{ Concreto } & $2^{\circ}$ Andar & 26,2 & 30,1 & 3,9 & 78,2 & $3: 40$ \\
\hline & & Cobertura & 26,8 & 31,2 & 4,4 & 75,3 & 4:00 \\
\hline & \multirow{2}{*}{ Cerâmico } & $2^{\circ}$ Andar & 26,0 & 30,8 & 4,8 & 73,1 & $3: 20$ \\
\hline & & Cobertura & 26,4 & 31,6 & 5,2 & 70,8 & $4: 00$ \\
\hline & & Temp. Externa & 20,3 & 38,1 & 17,8 & - & - \\
\hline
\end{tabular}




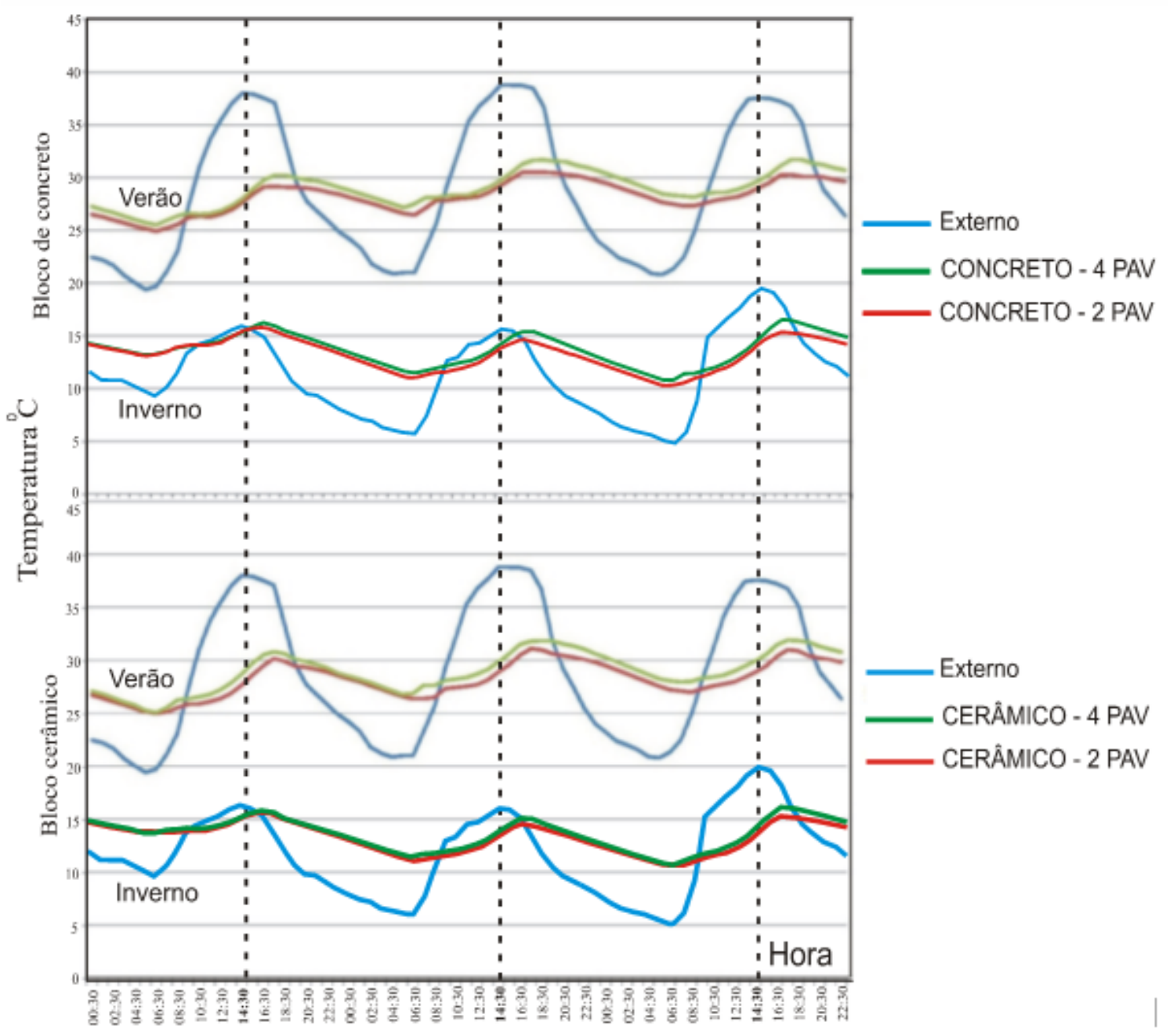

Figura 12: Variação da temperatura externa e interna no segundo e no quarto pavimento

Como a cobertura é a parte da edificação mais exposta à radiação solar, esta tem bastante influência na carga térmica ganha durante os períodos quentes. Por outro lado, as perdas térmicas nos períodos frios também são intensas por esse elemento construtivo, principalmente à noite. Observa-se que em ambas as edificações, tanto nos dias considerados de inverno como de verão, os ganhos de calor pela cobertura têm influência no comportamento térmico, pois esse pavimento apresenta temperaturas internas superiores durante todo o período, resultando médias de mínimas e de máximas maiores. As amplitudes térmicas também são maiores nesse andar, com menor amortecimento da variação térmica externa, indicador de pior desempenho térmico desse pavimento em relação ao segundo pavimento. No entanto, essa influência é pouco expressiva nas edificações analisadas, para o clima considerado e para o tipo de cobertura utilizada, com as maiores diferenças no inverno nas médias de mínimas de $0,3^{\circ} \mathrm{C}$ e nas máximas de $0,8^{\circ} \mathrm{C}$, e no verão de $0,6^{\circ} \mathrm{C}$ nas mínimas e de $0,8^{\circ} \mathrm{C}$ nas máximas.

A cobertura deve ser pensada com cuidado durante a fase de concepção do projeto, para que sejam buscadas alternativas corretas para redução da transmitância térmica e a existência de uma ventilação seletiva, que possa ser aberta nos períodos quentes para a retirada de calor e fechada nos períodos frios. Além dos problemas de conforto térmico no último pavimento, os exagerados ganhos térmicos pela cobertura podem causar dilatação térmica acentuada nas lajes de cobertura com aparecimento de fissuras nas paredes desse pavimento.

\section{CONCLUSÕES}

De acordo com os estudos desenvolvidos pode-se concluir que:

- Embora ocorram diferenças de temperaturas entre os ambientes dos edifícios construídos com o bloco estrutural de concreto e o cerâmico, essas diferenças são reduzidas. Isto indica que os dois tipos de blocos considerados neste estudo têm pouca influência no comportamento térmico das edificações estudadas, tanto no período de inverno como no de verão. Assim, para as edificações em alvenaria estrutural construídas com os mo- 
delos de blocos, com a cobertura considerada e para as orientações aqui analisadas, pode-se optar tanto pelo bloco estrutural de concreto quanto pelo bloco estrutural cerâmico na Zona Bioclimática 2 brasileira, sem que o comportamento térmico da edificação sofra alterações significativas.

- Analisando o comportamento térmico dos ambientes com fechamentos verticais com diferentes orientações é possível verificar a influência da radiação solar, tanto no inverno quanto no verão. Durante o inverno, em que a trajetória solar tem ângulos de alturas menores, observa-se maior influência da orientação solar dos fechamentos opacos sobre o comportamento térmico, ocorrendo as menores médias de mínimas e de máximas, e o maior amortecimento térmico, nos ambientes com parede cega para sul, e as maiores médias de temperaturas e menores amortecimentos em ambientes com a parede cega com orientação Norte. Já no verão, a influência da orientação solar sobre o comportamento térmico é menor, com diferenças menores nas temperaturas internas. Com a redução da radiação solar incidente na parede norte nesse período, as temperaturas máximas ocorrem em ambientes com parede cega para Sul, para ambos os blocos, e as temperaturas mínimas com a parede cega na orientação Norte.

- Com relação à análise da influência da cobertura, em ambos os períodos medidos, o amortecimento térmico mais elevado e a menor amplitude térmica interna foram medidos no segundo pavimento das edificações. Embora os valores medidos de temperatura indiquem que os ganhos de temperatura pela cobertura têm influência no comportamento térmico, em qualquer um dos dois edifícios, tanto no período de verão como no inverno, essa influência é reduzida nas edificações analisadas, para o clima considerado e para o tipo de cobertura utilizado.

- Analisando as propriedades térmicas dos fechamentos verticais executados com os dois tipos de blocos e comparando com as normas NBR 15220-2 [4] e NBR 15575-4 [2], considerando a Zona Bioclimática 2, foi possível perceber que o fechamento com bloco cerâmico apresentou valor de atraso térmico superior ao estipulado como limite pela NBR 15220-2 [4], enquanto que o fechamento com o bloco de concreto apresentou o valor de transmitância térmica superior ao limite estabelecido pela NBR 15575-4 [2], não alcançando o desempenho mínimo estabelecido pelo método simplificado dessa norma. Ou seja, de acordo com essas normas, ambos os blocos não seriam adequados para a Zona Bioclimática 2 brasileira analisada;

- Considerando apenas o período de medições desse trabalho, analisando pelos critérios do método de medições da NBR 15575-4 [2], considerando o dia com menor temperatura mínima $\left(5^{\circ} \mathrm{C}\right)$ no período de inverno medido e o ambiente com orientação mais desfavorável das edificações, encontra-se uma diferença entre as temperaturas mínimas interna e externa de $+4,3^{\circ} \mathrm{C}$ (bloco de concreto) e $+4,4^{\circ} \mathrm{C}$ (bloco de cerâmica), o que indicaria um desempenho mínimo para o inverno. Para o dia mais quente medido no verão, a diferença entre as temperaturas internas máximas no ambiente com orientação mais desfavorável e a temperatura máxima externa é de $-7,7^{\circ} \mathrm{C}$ (concreto) e $-6,9^{\circ} \mathrm{C}$ (cerâmica), o que indicaria um desempenho superior para ambos os tipos de fechamento.

\section{BIBLIOGRAFIA}

[1] ASSOCIAÇÃO BRASILEIRA DE NORMAS TÉCNICAS. NBR 15575-1: Edificações habitacionais Desempenho. Parte 1: Requisitos gerais. Rio de Janeiro. 2013.

[2] __ . NBR 15575-4: Edificações habitacionais - Desempenho. Parte 4: Requisitos para os sistemas de vedações verticais internas e externas. Rio de Janeiro, 2013.

[3] _ . NBR 15220-1: Desempenho térmico de edificações. Parte 1: Definições, símbolos e unidades. Rio de Janeiro, 2005.

[4] _ _ NBR 15220-2: Desempenho térmico de edificações. Parte 2: Método de cálculo da transmitância térmica, da capacidade térmica, do atraso térmico e do fator solar de elementos e componentes de edificações. Rio de Janeiro: ABNT, 2005.

[5] __ NBR 15220-3: Desempenho térmico de edificações. Parte 3: Zoneamento bioclimático brasileiro e diretrizes construtivas para habitações unifamiliares de interesse social. Rio de Janeiro, 2005.

[6] __ NBR 15812-1: Alvenaria Estrutural - Blocos cerâmicos. Parte 1: Projetos. Rio de Janeiro. 2010. $41 \mathrm{p}$.

[7] __ . NBR 15961-1: alvenaria estrutural - blocos de concreto. Parte 1: projeto. Rio de Janeiro: ABNT, 2011.

[8] _. . NBR 15961-2: alvenaria estrutural - blocos de concreto. Parte 2: execução e controle de obras. Rio de Janeiro: ABNT, 2011.

[9] A-HADHRAMI, L.M., AHMAD, A., "Assessment of thermal performance of different types of masonry bricks used in Saudi Arabia", AppliedThermalEngineeringJournal, v.29, pp.1123-1130, 2009. 
[10] CHICHIERCHIO, L. C., "Conforto ambiental: Desempenho térmico e acústico e proteção contra fogo", In: Associação Brasileira da Construção Industrializasa, Manual técnico de Alvenaria, ABCI/PROJETO,. pp 119-141, São Paulo:, 1990.

[11] GIVONI, B. "Comfort Climate Analysis and Building Design Guidelines", Rev. Energy and Buildings: v. 18, n. 1, p. 11-23, Lausanne, 1992.

[12] GRABARZ, R., SOUZA, L., PARSEKIAN, G. A. “Análise teórica do comportamento térmico do bloco e da alvenaria estrutural cerâmica e de concreto em habitações de interesse social - HIS" In III Simpósio Brasileiro de Qualidade do Projeto no Ambiente Construído, pp 12, Campinas, 2013.

[13] THOMAZ, E., HELENE, P. R. S., "Qualidade no projeto e na execução de alvenaria estrutural e de alvenarias de vedação em edifícios", Boletim Técnico, Dept. Construção Civil da Escola Politécnia da Universidade de São Paulo: BT/PCC/252, 2000, pp. 36.

[14] ZECHMEISTER, D. Estudo Para A Padronização Das Dimensões De Unidades De Alvenaria Estrutural No Brasil Através Do Uso Da Coordenação Modular. Dissertação de M.Sc., Programa de Pós-Graduação em Engenharia Civil da Universidade Federal do Rio Grande do Sul, Porto Alegre, 2005, 